\title{
BACIAS AÉREAS: UMA PROPOSTA METODOLÓGICA PARA O ESTUDO DA QULIDADE DO AR EM ÁREAS INFLUENCIADAS PELO RELEVO
}

\author{
Heitor Soares de Farias - heisofa@gmail.com
}

\begin{abstract}
Resumo
A Região Metropolitana do Rio de Janeiro (RMRJ), uma das mais polarizadas do país, atualmente possui mais de 11 milhões de habitantes, $74 \%$ de todo o Estado. O tecido urbano seguiu se expandindo por uma planície litorânea composta por maciços e baixadas, espremida entre a Serra do Mar e o Oceano Atlântico. O relevo acidentado, que no passado foi fundamental para a defesa do núcleo urbano, tem se revelado como uma grande barreira que dificulta tanto expansão da cidade como a circulação dos ventos. Com o objetivo de analisar a influência do relevo na circulação do ar, o presente estudo propõe-se a comparar a capacidade de dispersão de poluentes de diferentes localidades dentro da RMRJ, para comprovar ou refutar a existência de bacias aéreas, um conceito proposto para definir áreas formadas pela orientação das vertentes e da altitude do relevo, que influenciam na direção dos ventos de superfície e no transporte de poluentes. Para alcançar os objetivos propostos utilizou-se a modelagem numérica atmosférica: o modelo Brazilian Regional Atmospheric Modeling System (BRAMS) e o Trajetórias Cinemáticas 3D, que juntos foram capazes de representar a influência do relevo na dispersão dos poluentes atmosféricos e na formação as bacias aéreas.
\end{abstract}

Palavras chave: Poluição do ar, bacias aéreas, modelos atmosféricos, Arco Metropolitano, RMRJ.

AIR BASIN: A PROPOSED METHODOLOGY FOR THE STUDY OF AIR QUALITY IN THE INFLUENCED AREA BY RELIEF

\section{Abstract}

The Metropolitan Region of Rio de Janeiro (RMRJ), one of the most polarized country, currently has over 11 million inhabitants, $74 \%$ of the entire state. The expanding urban followed by a coastal plain lowlands and consists of massive, sandwiched between the Coast Range and the Atlantic Ocean. The rugged terrain, which in the past was essential to the defense of the urban core, has been revealed as a major barrier that hinders both expansion of the city as the movement of winds. With the objective of analyzing the influence of the relief in air circulation, this study proposes to compare the dispersal of pollutants from different locations within the region, to prove or disprove the existence of air basins, a concept proposed to define areas formed by the orientation of the slopes and altitude relief, influencing the direction of surface winds and the transport of pollutants. To achieve the proposed objectives, we used the numerical atmospheric modeling: the model Brazilian Regional Atmospheric Modeling System (BRAMS) and Cinematic 3D trajectories, which together were able to represent the influence of the relief in the dispersion of air pollutants and training air basins.

Keywords: Air pollution, air basins, atmospheric models, Metropolitan Arch, RMRJ.

\section{INTRODUÇÃO}

A cidade do Rio de Janeiro foi fundada no alto do Morro do Castelo, localizado em uma planície recoberta por maciços litorâneos. A presença da Baía de Guanabara foi importante, pois as águas calmas permitiam o ancoradouro e protegiam as embarcações das tempestades. Além da baía, que possui uma entrada estreita, o terreno bastante acidentado foi fundamental para garantir a segurança da cidade no início de sua ocupação. No entanto, ao longo da história o relevo tem se revelado como uma grande barreira que dificulta tanto expansão da cidade como a circulação dos ventos, o que traz sérios problemas à saúde dos habitantes.

O desmonte do Morro do Castelo, berço da cidade, no início do século XX, é uma das provas desse efeito. A justificativa oficial do prefeito à época, Carlos Sampaio, era de que o morro seria derrubado em nome da higiene e aeração, 
embora se saiba que a retirada de um bairro proletário incrustado em um centro valorizado também fosse outro motivo importante (ABREU, 1987).

O tecido urbano seguiu expandindo-se espremido entre a serra e o oceano. Atualmente, a Região Metropolitana do Rio de Janeiro (RMRJ), uma das mais polarizadas do país, possui mais de 11 milhões de habitantes, $74 \%$ de todo 0 Estado, e só a cidade do Rio de Janeiro tem mais de 6 milhões de habitantes (CENSO, 2010). Assim, a planície litorânea encontra-se quase que completamente urbanizada, mais de $99 \%$ da RMRJ é urbana, sendo o maior grau de urbanização e densidade demográfica entre as regiões metropolitanas do país (INEA, 2009).

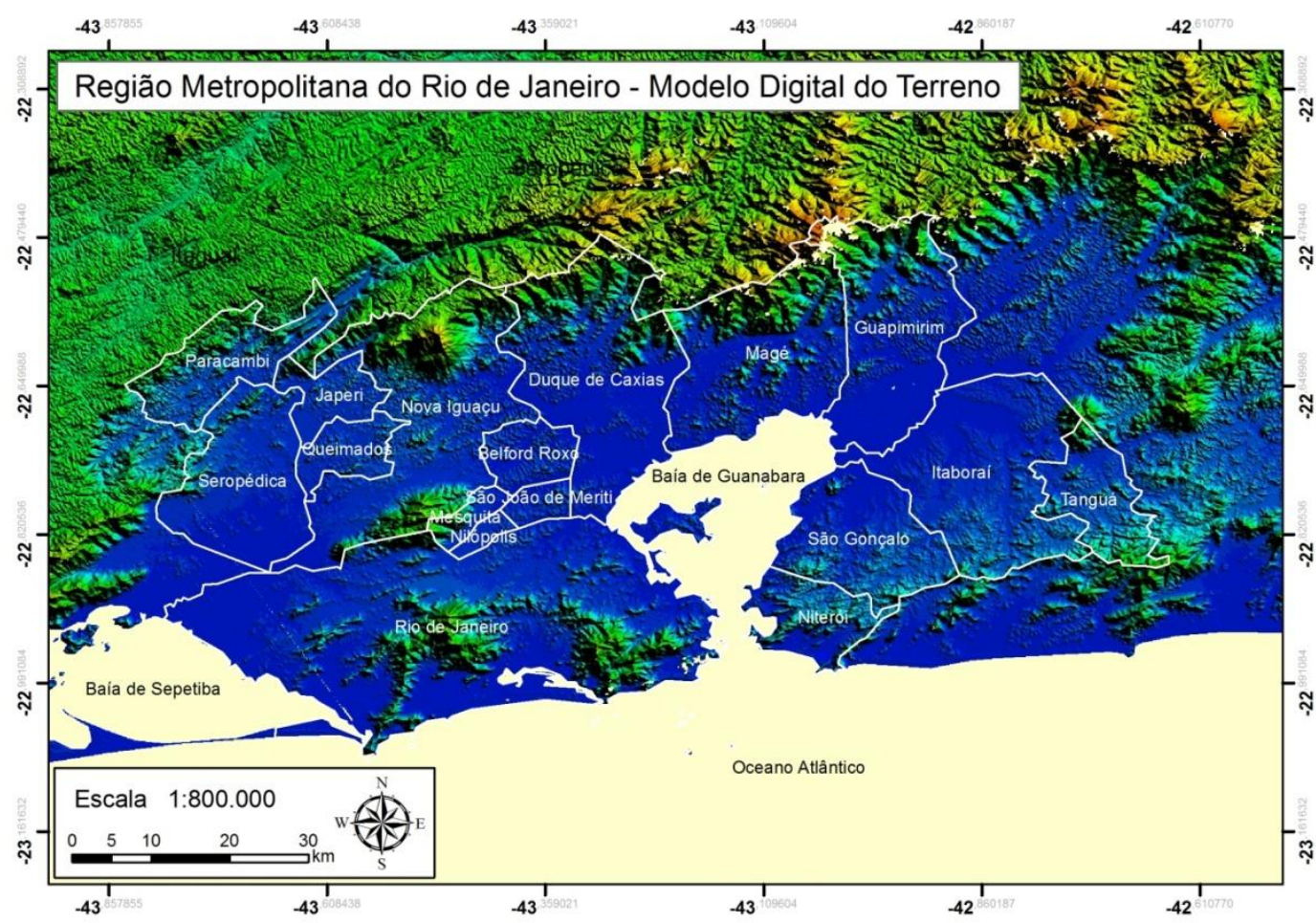

Figura 1 - O relevo na RMRJ

Na planície ocupada pela RMRJ, que é rodeada pela Serra do Mar, que eleva-se a 900 metros de altitude em média, também encontram-se alguns maciços litorâneos, sendo que os três maiores - Tijuca, Pedra Branca e GericinóMendanha - também apresentam altitudes superiores a 900 metros, e estão localizados no município do Rio de Janeiro. Assim, pode-se dizer que a topografia da RMRJ impõe resistência ao escoamento atmosférico, reduz a velocidade do vento e impede que a brisa marítima alcance os bairros e municípios localizados em determinados pontos, contribuindo para a estagnação de poluentes (OLIVEIRA, 2004; FARIAS, 2012).

No Rio de Janeiro, o Instituto Estadual do Ambiente (Inea), resultado da fusão da Superintendência Estadual de Rios e Lagoas (Serla), Instituto Estadual de Florestas (IEF) e Fundação Estadual de Engenharia do Meio Ambiente (Feema), realiza estudos da qualidade do ar desde 1967, quando foram instaladas as primeiras estações de monitoramento $e$, os resultados obtidos refletiram o comprometimento da qualidade do ar de várias áreas (INEA, 2007). 
Como a qualidade do ar de uma região está relacionada aos fenômenos atmosféricos observados na área, pois fatores meteorológicos como ventos, chuvas e instabilidade do ar interferem na qualidade do ar (CETESB, 1999), e, no Rio de Janeiro os maciços atuam como barreiras físicas aos ventos predominantes, o Inea divide a RMRJ em quatro sub-regiões, quando analisa a qualidade do ar (INEA, 2007, 2008, 2009).

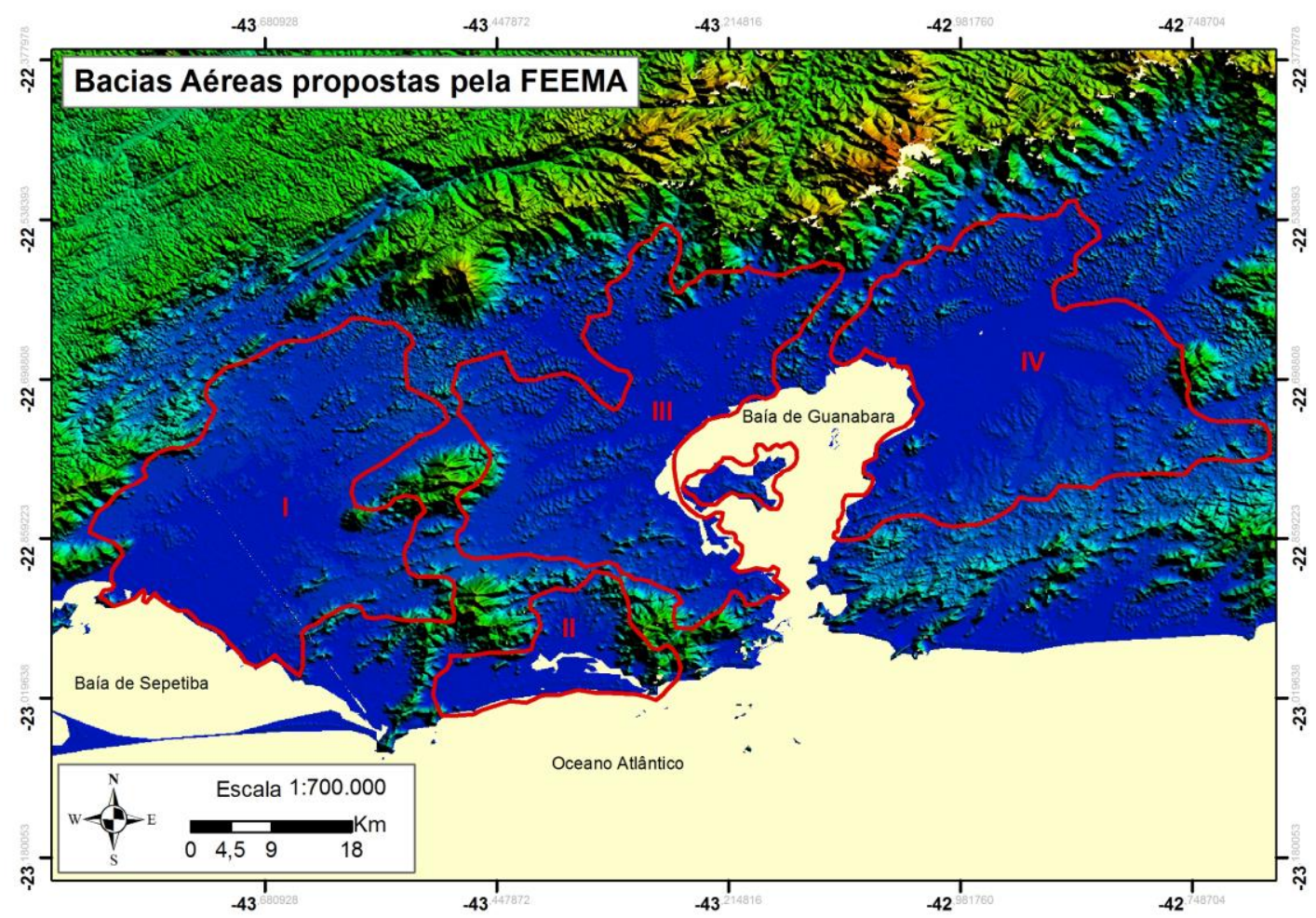

Figura 2 - As quatro bacias aéreas e seus limites.

No Inventário de Fontes Emissoras de Poluentes Atmosféricos da Região Metropolitana do Rio de Janeiro (2004), a nomenclatura utilizada para designar as sub-regiões é Bacia Aérea, embora esta não apareça nos documentos mais recentes do Inea $(2007,2008,2009)$. Este termo define as áreas com distintas concentrações de poluentes, formadas em consequência da orientação das vertentes e da altitude do relevo da RMRJ, que influenciam na direção dos ventos de superfície e dificultam a dispersão de poluentes.

Para Oliveira (2004, p.70) "uma bacia aérea, embora o nome sugira um volume da atmosfera, é uma área cujo relevo, delimitado por uma cota altimétrica mínima, dificulta a dispersão de poluentes gerados pelas atividades socioeconômicas".

Também deve ser considerada a base da atmosfera que, ao ser delimitada pelo relevo (cota mínima de 100 metros), coloca as diferentes áreas do espaço geográfico da bacia aérea sob a mesma condição quanto a qualidade do ar. Por isso as bacias aéreas são consideradas unidades de gerenciamento da qualidade do ar (OLIVEIRA, 2004; FARIAS, 2012).

A RMRJ possui quatro bacias aéreas que têm a qualidade do ar comprometida devido à presença da segunda maior concentração de indústrias, veículos, e de outras fontes de poluentes atmosféricos do país: 
> Bacia aérea I: localizada na zona oeste da RMRJ, com cerca de $730 \mathrm{~km}^{2}$.

> Bacia aérea II: localizada no município do Rio de Janeiro, envolve as regiões administrativas de Jacarepaguá e Barra da Tijuca, com cerca de $140 \mathrm{~km}^{2}$.

> Bacia aérea III: compreende a zona norte do município do Rio de Janeiro e grande parte dos municípios da baixada Fluminense, com cerca de 700 km².

> Bacia aérea IV: localizada a leste da baía de Guanabara possui $830 \mathrm{~km}^{2}$.

\begin{tabular}{c|ccccccccccc}
\hline \multirow{2}{*}{$\begin{array}{c}\text { Bacia } \\
\text { aérea }\end{array}$} & \multicolumn{6}{c}{ Poluentes - Taxa de emissão (ton/ano x 1.000 e \%) } \\
\cline { 2 - 11 } & \multicolumn{2}{c}{$\mathrm{MP}_{10}$} & \multicolumn{2}{c}{$\mathrm{SO}_{2}$} & \multicolumn{2}{c}{$\mathrm{NO}_{\mathrm{x}}$} & \multicolumn{2}{c}{$\mathrm{CO}$} & \multicolumn{2}{c}{$\mathrm{HC}$} \\
\hline I & 5,9 & $58 \%$ & 21,5 & $39 \%$ & 14,6 & $50 \%$ & 0,9 & $15 \%$ & 0,3 & $1 \%$ \\
II & 0,4 & $4 \%$ & 0 & $0 \%$ & 0,1 & $0 \%$ & 0,1 & $2 \%$ & 0,7 & $3 \%$ \\
III & 2,5 & $25 \%$ & 29,4 & $54 \%$ & 13,3 & $45 \%$ & 2,8 & $45 \%$ & 24,4 & $95 \%$ \\
IV & 1,4 & $14 \%$ & 3,8 & $7 \%$ & 1,3 & $4 \%$ & 2,4 & $38 \%$ & 0,1 & $1 \%$ \\
Total & 10,2 & $100 \%$ & 54,7 & $100 \%$ & 29,3 & $100 \%$ & 6,2 & $100 \%$ & 25,6 & $100 \%$ \\
\hline
\end{tabular}

FEEMA (2004)

Tabela 1 - Taxa de emissão de poluentes na região metropolitana do Rio de Janeiro, por bacias aéreas (2004)

Os dados de qualidade do ar mostram que a Bacia Aérea III é a que apresenta as maiores taxas de emissões de dióxido de enxofre (SO2), monóxido de carbono (CO) e hidrocarbonetos (HC). Já em relação aos óxidos de nitrogênio (NOX) e material particulado (MP10) é a Bacia Aérea I que apresenta as maiores taxas de emissões. Esta bacia tem a previsão de maior crescimento industrial da RMRJ para os próximos anos, quando estiverem concluídas as obras do Arco Metropolitano e da Companhia Siderúrgica do Atlântico (CSA), concentrando um grande fluxo de veículos para esta área da cidade. No entanto a CSA já apresentou, mais de uma vez, problemas técnicos que resultaram na emissão de material particulado sobre o bairro de Santa Cruz, vizinho à siderúrgica, atingindo os moradores, sendo amplamente divulgado nas ocasiões.

A bacia aérea I apresenta as maiores emissões material particulado na RMRJ, e continua recebendo novas unidades industriais com grande potencial poluidor, como é o caso da CSA, uma siderúrgica. O material particulado é extremamente nocivo à saúde humana, pois segundo a bibliografia médica pode provocar aumento na mortalidade mesmo quando as concentrações médias estão dentro dos padrões internacionais de qualidade do ar (SCHIMMEL \& MURAWSKI, 1976; MAZUMDAR \& SUSSMAN, 1983; CLANCY et al., 2002; DAUMAS et al., 2004), sendo as crianças e os idosos os mais atingidos por doenças respiratórias (SALDIVA et al., 1995; BRAGA et al., 1999; GOUVEIA e FLETCHER, 2000b; FREITAS et al., 2004; GOUVEIA et al., 2006).

Desta maneira o presente trabalho objetiva analisar a influência do relevo na circulação do ar da RMRJ, comparando a capacidade de dispersão de poluentes de diferentes áreas, para comprovar ou refutar a existência de bacias aéreas. 


\section{MATERIAIS E MÉTODOS}

Para alcançar os objetivos propostos utilizou-se a modelagem numérica atmosférica. Para reproduzir a circulação dos ventos optou-se pelo modelo Brazilian Regional Atmospheric Modeling System (BRAMS). Os resultados foram aplicados em outro modelo, o Trajetórias Cinemáticas 3D, que calcula as trajetórias de parcelas do ar em três dimensões, representando a influência do relevo na dispersão dos poluentes atmosféricos e na formação as bacias aéreas. O BRAMS é um modelo meteorológico de mesoescala desenvolvido com alguns ajustes para representar o estado da atmosfera dos trópicos, apresentando bons resultados para as condições atmosféricas brasileiras. Este modelo possui três grades aninhadas como recurso para calcular os ventos em diferentes resoluções espaciais para uma mesma área, o que possibilitou analisar as bacias aéreas com mais detalhes. É importante destacar que nesse nível de resolução, alcançado pela grade 3 , são reproduzidas por setas a velocidade e direção dos ventos, além da altimetria do relevo, diferenciada por cores.

Com o modelo BRAMS foram feitas simulações para dois dias: 12 de janeiro e 11 de julho de 2010, verão e inverno, respectivamente. Esses dias foram representativos das condições sinóticas predominantes no Rio de Janeiro, quando o Anticiclone Subtropical do Atlântico Sul (ASAS) está atuando. O ASAS é um sistema de grande escala quase estacionário que atua durante o ano todo, mas que apresenta pequenas variações em sua posição, dependendo da estação. No verão o forte aquecimento da atmosfera sobre o continente faz com que o ASAS seja mais intenso sobre o mar, onde a temperatura é mais baixa, atuando com menos intensidade sobre o continente. Já no inverno, quando o continente está mais frio que o mar, o ASAS avança sobre o continente, atuando intensamente sobre o Rio de Janeiro. A forte subsidência no centro do ASAS aumenta a temperatura do ar por compressão, inibe a formação de nebulosidade e, por conseguinte, a precipitação, atuando como barreira aos avanços do Anticiclone Polar Migratório (APM) que se desloca das altas latitudes em direção às latitudes baixas.

Para simular as trajetórias dos poluentes emitidos na RMRJ optou-se pelo modelo cinemático tridimensional e método não convectivo desenvolvido por Freitas (1999), alimentado com dados sobre o campo de vento gerado pelo modelo BRAMS. Como trata-se de um modelo tridimensional representado em uma superfície, a altitude de uma partícula ou poluente é representada por uma escala de cores que varia do azul marinho, para altitudes de 0 até 100 metros, ao rosa, para altitudes entre 1900 e 2000 metros, ao longo da trajetória de parcelas de ar.

As trajetórias foram simuladas em dois horários, 9 e 18 horas, para a altura de 0 metros, que corresponde ao escapamento dos veículos, para os meses de janeiro e julho, para verificar o comportamento das trajetória dos poluentes nas estações de verão e inverno na RMRJ. As simulações foram feitas para cinco pontos de emissão - distribuídos pelas bacias aéreas 1,3 e 4 - que correspondem ao entroncamento do Arco Metropolitano com rodovias federais (Figura 3):

- Ponto 1: BR101 em Itaguaí (22, 7667 S e 42, 9226 W) - bacia aérea I;

- Ponto 2: BR116 em Seropédica, (22, 6564 S e 43, 0883 W) - bacia aérea I;

- Ponto 3: BR040 em Caxias, (22, 6718 S e 43, 2857 W) - bacia aérea III;

- Ponto 4: BR465 em Magé, (22, 7306 S e 43, 7158 W) - bacia aérea IV;

- Ponto 5: BR101 em Itaboraí, (22, 8728 S e 43, 8094 W) - bacia aérea IV. 


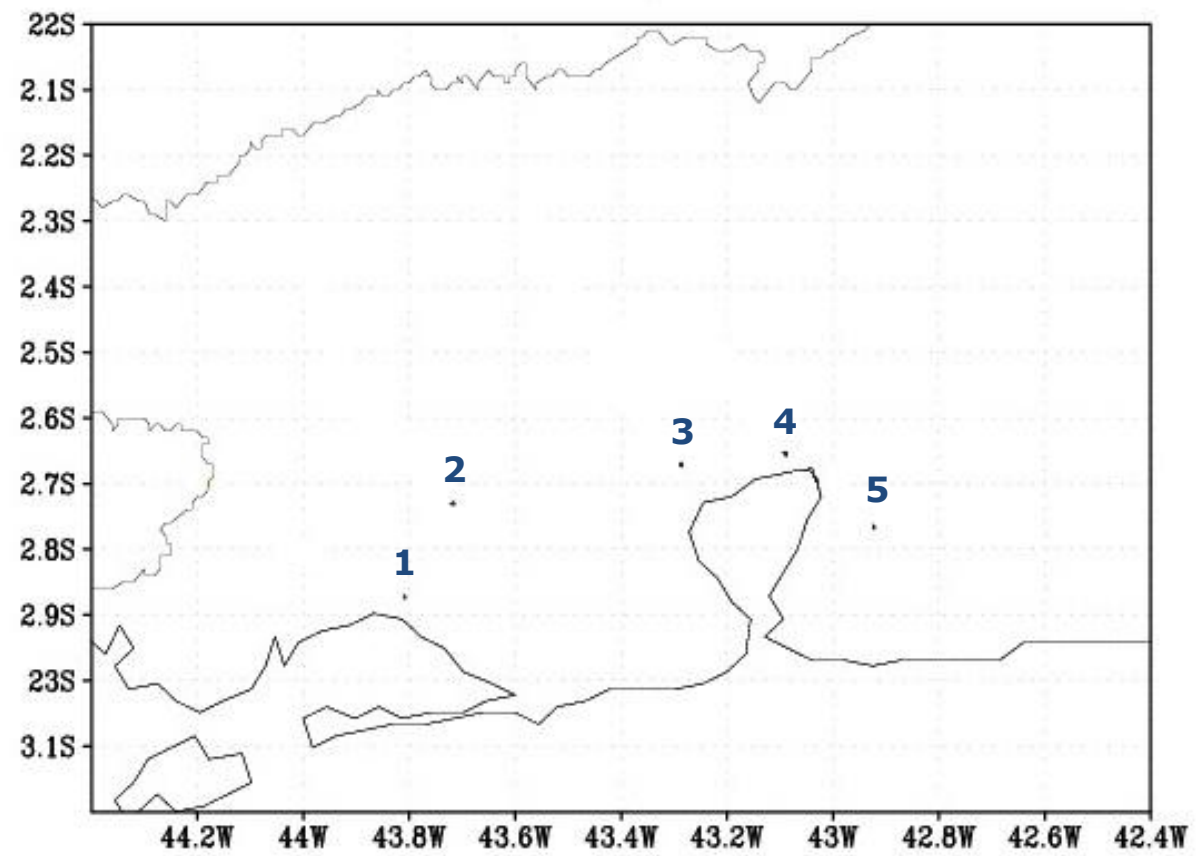

Figura 3 - Localização dos pontos de simulação das trajetórias 3D a partir do Arco Metropolitano.

\section{Resultados e Discussão}

No verão, o dia 12 de janeiro de 2010 foi de forte calor. Na carta de superfície deste dia pode-se observar o ASAS sobre o oceano Atlântico, próximo à costa brasileira, e uma frente fria sobre a Argentina, quase chegando ao sul do Brasil (Figura 5).

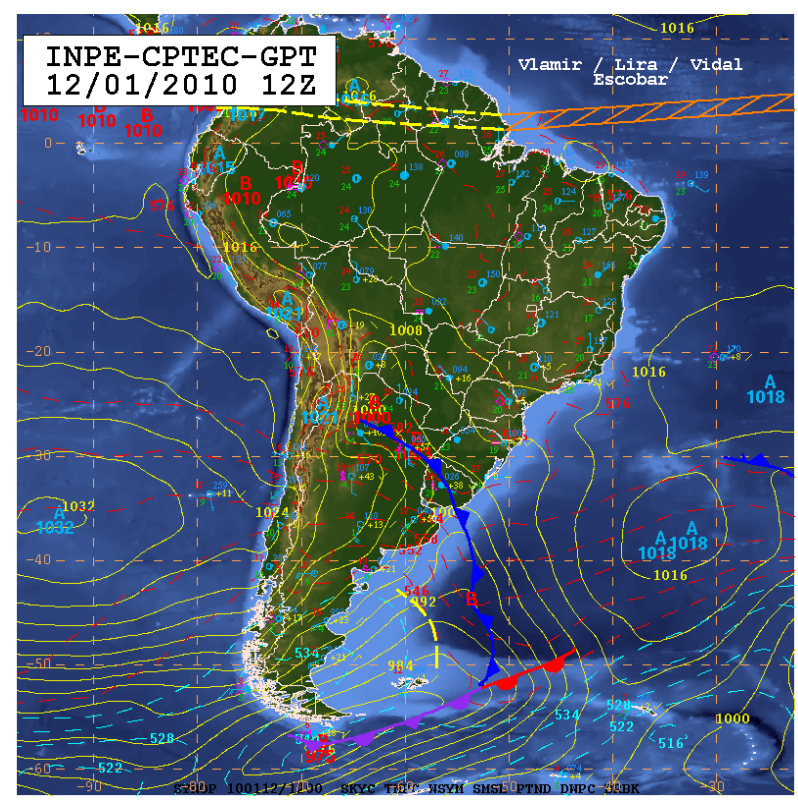

Figura 5 - Carta de superfície do dia 12 de janeiro de 2010, 12 UTC 
No horário da manhã observam-se ventos paralelos à costa, sobre o mar, e no planalto, devido ao maior aquecimento do topo da Serra do Mar, ventos subindo a encosta em direção ao cume (brisa de vale). Na planície litorânea observa-se o efeito da brisa marítima nas bacias aéreas III e IV, enquanto que na bacia aérea I os ventos vindos do mar têm a velocidade reduzida em função do relevo (Figura 6).

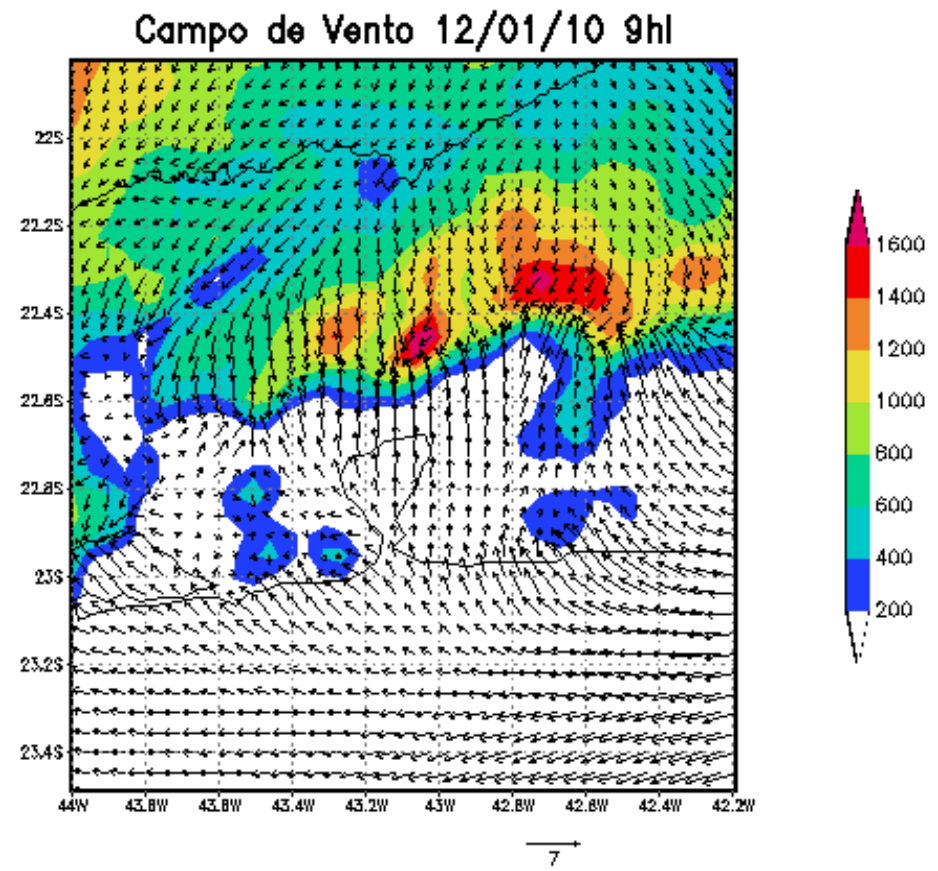

Figura 6 - Escoamento atmosférico do dia 12/01/2010, 9 horas local

Durante a manhã as trajetórias emitidas das bacias aéreas III e IV (pontos 3, 4, 5), devido à presença do relevo, deslocam-se para norte em baixa altitude durante o início do percurso, fazendo com que os poluentes circulem próximos ao solo, contaminando o ar por mais tempo dentro da bacia aérea de emissão.

Ao ascender para ultrapassar a Serra do Mar, as trajetórias passam a receber influência da circulação de grande escala e se elevam até 2000 metros do solo. $\mathrm{Na}$ bacia aérea I (pontos 1 e 2), onde os ventos estavam mais fracos, as trajetórias se elevaram menos e chegaram no máximo a 1500 metros devido a presença do maciço (Figura 7).

No fim da tarde percebe-se uma mudança na circulação atmosférica. Diferentemente do horário da manhã, a brisa marítima influencia mais as bacias aéreas I e III com um fluxo bastante intenso, e menos na bacia aérea IV, na área mais protegida pelo relevo (Figura 8 ). 


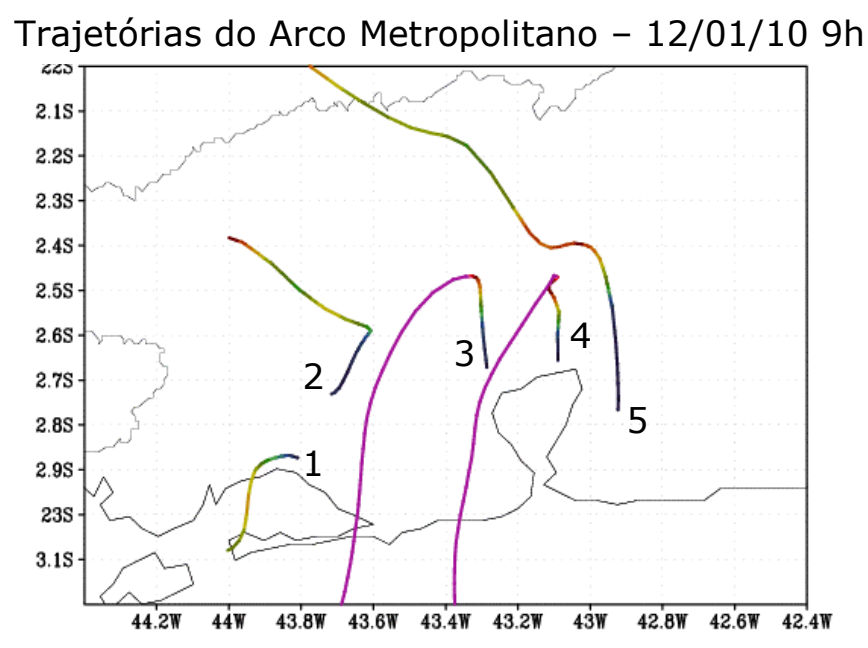

$\begin{array}{lllllllllllllllllllllll}0.1 & 0.2 & 0.3 & 0.4 & 0.5 & 0.6 & 0.7 & 0.8 & 0.9 & 1 & 1.1 & 1.2 & 1.3 & 1.4 & 1.5 & 1.6 & 1.7 & 1.8 & 1.9 & 2\end{array}$

Figura 7 - Trajetórias simuladas para o dia 12/01/2010, 9 horas local

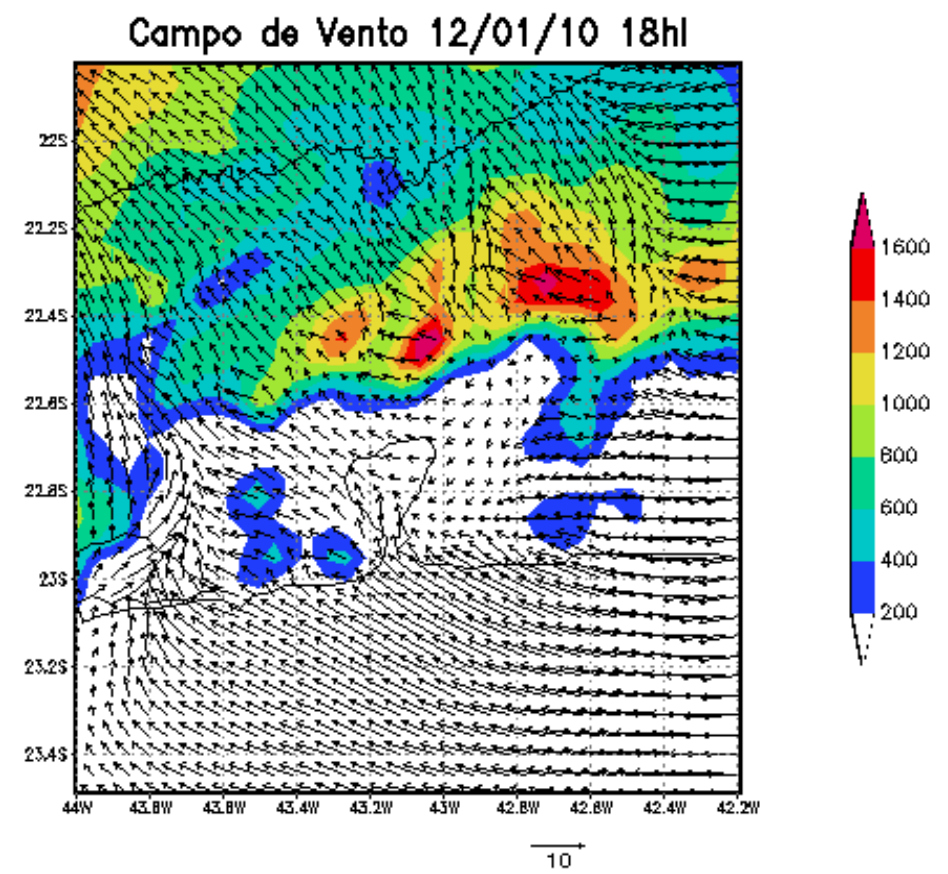

Figura 8 - Escoamento atmosférico do dia 12/01/2010, 18 horas local

No fim da tarde as trajetórias deslocam-se em baixa altitude durante grande parte do percurso, alcançando o máximo de 800 metros do solo, principalmente nos pontos 3, 4 e 5, após superarem a Serra do Mar. Nesta simulação percebese que as trajetórias avançaram mais sobre o continente do que no horário da manhã, levando poluentes para localidades distantes das fontes de emissão, circulando bem próximas à superfície, o que pode gerar sérios problemas à saúde da população (Figura 9). 


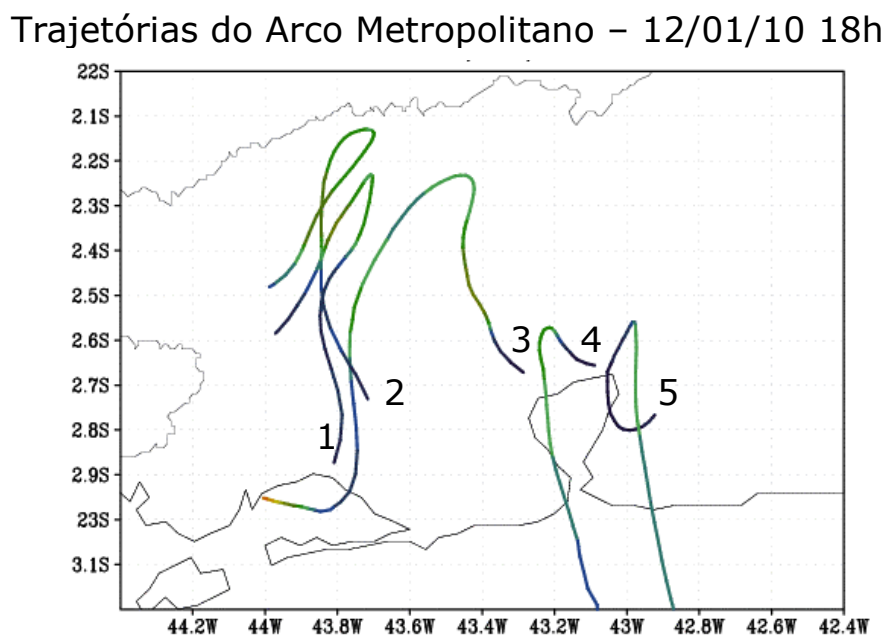

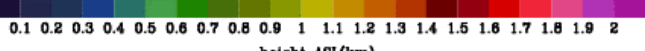 height ASL $(\mathrm{km})$}

Figura 9 - Trajetórias simuladas para o dia 12/01/2010, 18 horas local

No inverno, o dia 11 de julho de 2010 foi de bastante calor, uma temperatura agradável para a estação. Na carta de superfície deste dia observa-se o ASAS sobre o oceano Atlântico, próximo à costa brasileira, muito mais forte do que no verão (Figura 10).

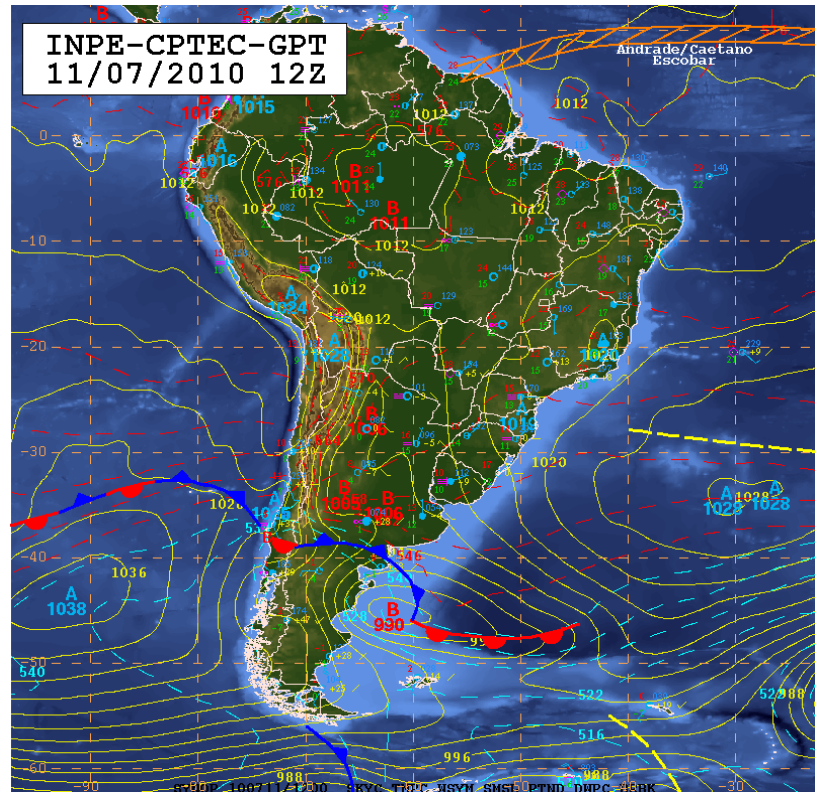

Figura 10 - Carta de superfície do dia 11 de julho de 2010, 12 UTC

Durante a manhã os ventos seguiram paralelos à costa do Rio de Janeiro, e têm sua velocidade reduzida pelo relevo, sendo as bacias aéreas III e IV atingidas por ventos mais fracos, e a bacia aérea I, praticamente isolada da sua atuação (Figura 11). 


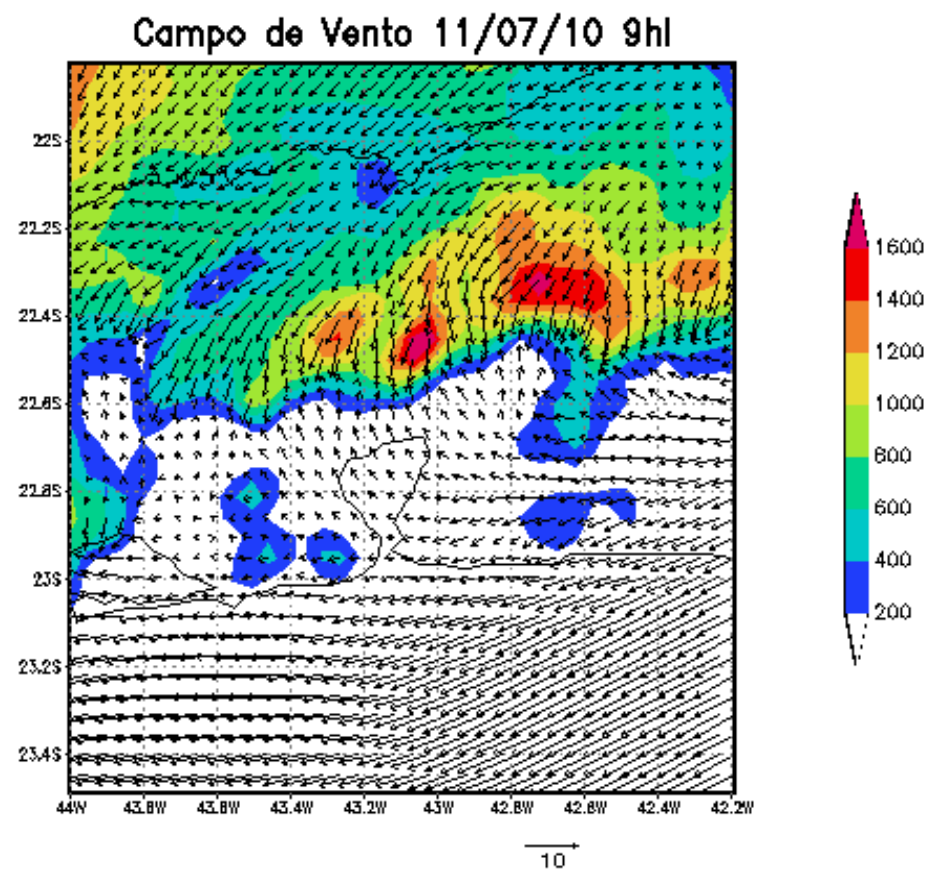

Figura 11 - Escoamento atmosférico do dia 11/07/2010, 9 horas local

Neste horário as trajetórias têm comportamento semelhante ao observado nas manhãs de verão, no entanto elevaram-se menos. Em todos os pontos as trajetórias emitidas deslocam-se em baixa altitude no início do percurso, e na bacia aérea I (pontos 1 e 2 ) elevaram-se menos que nas demais bacias aéreas (Figura 12).
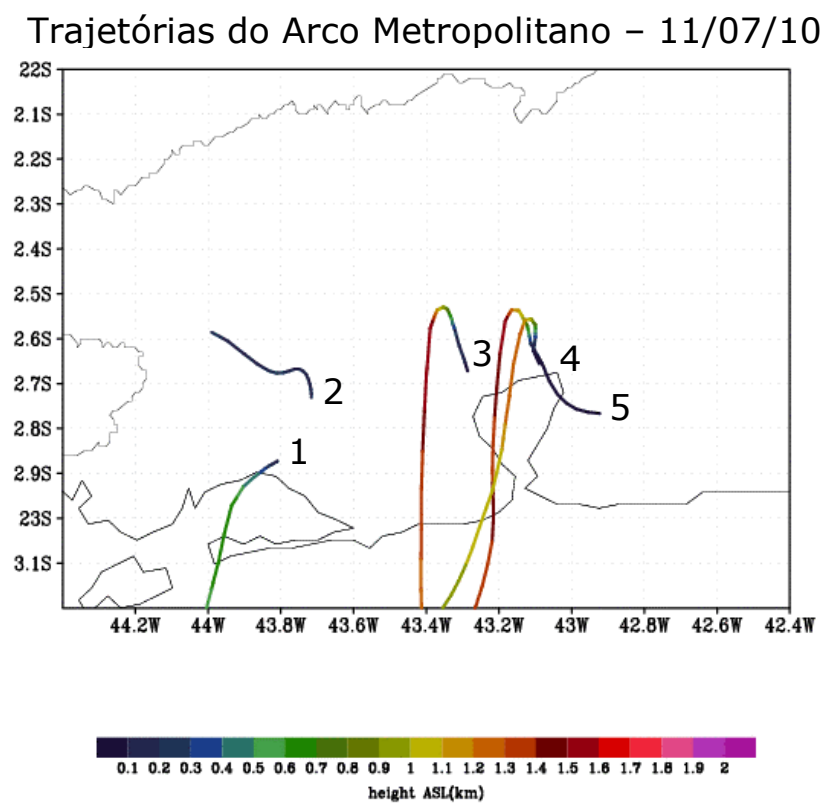

Figura 12 - Trajetórias simuladas para o dia 11/07/2010, 9 horas local

No fim da tarde o escoamento atmosférico é alterado, assim como no verão, e todas as bacias aéreas estão sob o domínio da brisa marítima (Figura 13). 


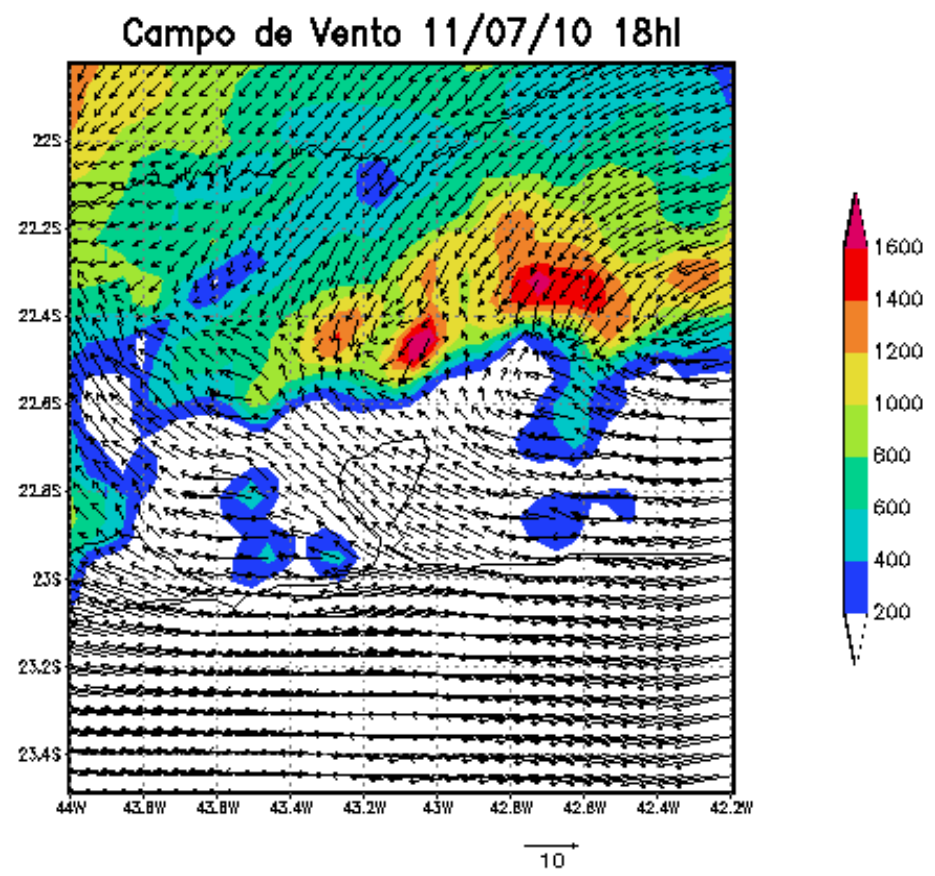

Figura 13 - Escoamento atmosférico do dia 11/07/2010, 18 horas local

No fim da tarde as trajetórias têm deslocamento semelhante ao observado pela manhã, no entanto se elevam menos. As trajetórias emitidas das bacias aéreas III e IV (pontos 3, 4 e 5) deslocam-se em baixa altitude para norte e ao transporem a Serra do Mar são influenciadas pela circulação de grande escala, dirigindo-se para o oceano. Já as trajetórias emitidas da bacia aérea I (pontos 1 e 2) ficam próximas à superfície (Figura 14).

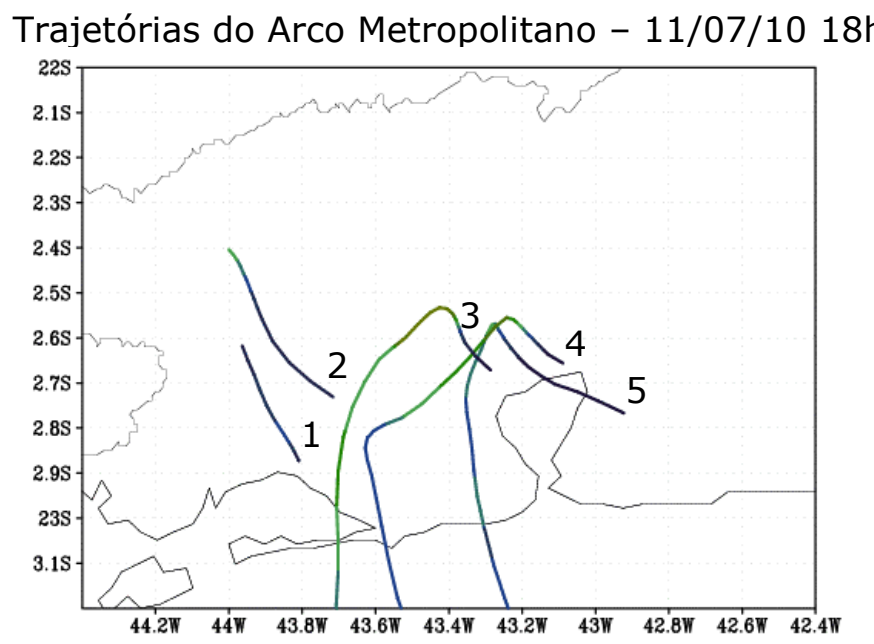

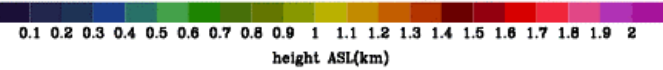

Figura 14 - Trajetórias simuladas para o dia 11/07/2010, 18 horas local 


\section{Conclusões}

A análise do campo de vento e o cálculo das trajetórias permitiram verificar que no verão os poluentes tendem a ascender mais devido à maior instabilidade da atmosfera e a maior espessura da camada de mistura, principalmente no início da manhã, quando os poluentes são dispersados com maior facilidade. No final da tarde as trajetórias ganham menos altitude e, em função da ação da brisa marítima, os poluentes são transportados para o interior do continente onde está a Serra do Mar, que delimita as bacias aéreas I, III e IV, comprometendo a qualidade do ar dos moradores dos municípios do interior do Estado - Baixada Fluminense e municípios serranos.

No inverno as trajetórias quase não elevaram-se em função da maior estabilidade e menor espessura da camada de mistura, ficando concentradas próximas à superfície, dentro das bacias aéreas de emissão, afetando a saúde da população. Nesta estação, sob a ação mais intensa do ASAS, as trajetórias avançam menos para o interior do Estado do Rio de Janeiro, ficando concentradas sobre a RMRJ e direcionam-se para o oceano (bacias aéreas III e IV).

Também foi possível observar que em todas as simulações realizadas com o modelo Trajetórias Cinemáticas 3D os poluentes deslocam-se em baixa altitude no início do percurso, sem conseguir ultrapassar os 100 metros de altitude, o que comprova o efeito do relevo enquanto barreira física, impedindo a ação dos ventos.

Nas bacias aéreas III e IV, os poluentes são carreados em direção à Serra do Mar e forçados à ascender. Ao ultrapassarem esta barreira, os poluentes passam a ser influenciados pelos ventos de grande escala e voltam-se para a planície, mas desta vez em grande altitude, o que favorece a dispersão. Nessas bacias aéreas, o relevo, que no início inibe a ação dos ventos, ao ser associado às brisas marinhas, funciona como "rampa de lançamento" para os poluentes, que ascendem por convecção.

$\mathrm{Na}$ bacia aérea I observou-se maior dificuldade para dispersar os poluentes devido à presença do Maciço da Pedra Branca, o que deixa esta bacia aérea menos expostas à ação dos ventos de leste que sopram paralelos ao litoral do Rio de Janeiro. Outro fator importante é a menor altura da Serra do Mar no limite norte desta bacia aérea, canalizando os ventos de grande escala o que desfavorece o efeito de convecção observado nas demais bacias aéreas da RMRJ.

Assim, conclui-se que a posição e a orientação do relevo têm grande influência na circulação dos ventos e, por conseguinte, na capacidade de dispersão/concentração de poluentes em determinadas áreas da RMRJ. Em todas as simulações as trajetórias emitidas na bacia aérea I alcançaram menor altitude, destacando-se negativamente por apresentar dificuldades para dispersar poluentes. Este fato torna importante o mapeamento e identificação de bacias aéreas para o estudo e monitoramento da qualidade do ar. Áreas com concentração de indústrias que emitem poluentes atmosféricos e onde o relevo tem grande altitude, podem apresentar períodos de estagnação do ar e provocar sérios danos à saúde da população.

\section{Referências Bibliográficas}

ABREU, M. A. A evolução urbana do Rio de Janeiro. Rio de Janeiro, IPP,156p, 1987. BRAGA, A. L.; CONCEIÇÃO, G. M.; PEREIRA L. A.; KISHI, H. S.; PEREIRA J. C. \& ANDRADE, M. F. Air pollution and pediatric respiratory hospital admissions in São Paulo, Brazil. Journal Environmental Medicine; 1:95-102, 1999. 
CENSO DEMOGRÁFICO 2010. IBGE. Disponível em www.ibge.org.br

CETESB, "Relatório Anual da Qualidade do Ar - 1999".

CLANCY L., GOODMAN P., SINCLAIR H., DOCKERY D. W. Effect of air-pollution control on death rates in Dublin, Ireland: an intervention study. Lancet, 360(9341):12104, 2002.

DAUMAS, R. P.; MENDONÇA, G. A. S. \& LEON, A. P. Poluição do ar e mortalidade em idosos no município do Rio de Janeiro: análise de série temporal. Cadernos de Saúde Pública Rio de Janeiro; 20:311-319, 2004.

FARIAS, H. S. Espaços de risco à saúde humana na região metropolitana do Rio de Janeiro: um estudo das trajetórias de poluentes atmosféricos do Arco Metropolitano, CSA e COMPERJ. Tese de Doutorado. Instituto de Geociências da Universidade Federal Fluminense, Niterói. 149p, 2012.

FEEMA - Fundação Estadual de Engenharia do Meio Ambiente. Inventário de fontes emissoras de poluentes atmosféricos da região metropolitana do Rio de Janeiro. Rio de Janeiro. FEEMA, 26p, 2004.

FREITAS, C.; BREMNER, S. A.; GOUVEIA, N.; PEREIRA, L. A. A. \& SALDIVA, P. H. N. Internações e óbitos e sua relação com a poluição atmosférica em São Paulo, 1993 a 1997. Revista de Saúde Pública:USP; 38(6):751-7, 2004.

FREITAS, S. R. Modelagem numérica do transporte e das emissões de gases traços e aerossóis de queimadas no cerrado e floresta tropical da América do Sul. Tese de doutorado. Instituto de Física da Universidade de São Paulo, São Paulo. $185 p, 1999$.

GOUVEIA, N. \& FLETCHER, T. Time series analysis of air pollution and mortality: effects by cause, age and socioeconomic status. J Epidemiol Community Health; 54:750-5, 2000a.

GOUVEIA, N.; FREITAS, C. U.; MARTINS, L. C.; MARCILIO, I. O. Hospitalizações por causas respiratórias e cardiovasculares associadas à contaminação atmosférica no Município de São Paulo, Brasil. Cad. Saúde Pública, Rio de Janeiro, 22(12):26692677, 2006.

INEA - Instituto Estadual do Ambiente. Relatório Anual de Qualidade do Ar. 91p. 2007.

INEA - Instituto Estadual do Ambiente. Relatório Anual de Qualidade do Ar. 105p. 2008.

INEA - Instituto Estadual do Ambiente. Relatório Anual de Qualidade do Ar. 108p. 2009.

MAZUMDAR, S. \& SUSSMAN, N. Relationships of air pollution to health: Results from the Pittsburgh Study. Archives of Environmental Health; 38: 17-24, 1983.

OLIVEIRA, J. L. F. Análise espacial e modelagem atmosférica: contribuições ao gerenciamento da qualidade do ar da bacia aérea III da região metropolitana do Rio de Janeiro. Tese de Doutorado - COPPE - Universidade Federal do Rio de Janeiro, Rio de Janeiro. 144p, 2004.

SALDIVA, P. H.; POPE, C. A.; SCHWARTZ, J.; DOCKERY, D. W.; LICHTENFELS, A. J. \& SALGE, J. Air pollution and mortality in elderly people: a time-series study in Sao Paulo, Brazil. Arch Environ Health; 50:159-63, 1995.

SCHIMMEL, H. \& MURAWSKI, T. J. The relation of air pollution to mortality. Journal of Occupation Medicine, 18: 316-333, 1976. 